\title{
Antibiotic resistance patterns of urinary tract pathogens in children from Central Romania
}

\author{
CARMEN DUICU $^{1}$, IULIA COZEA $^{2}$, DAN DELEAN $^{3}$, ANDREEA ALEXANDRA ALDEA $^{4}$ and CORNELALDEA $^{3}$ \\ ${ }^{1}$ Department of Pediatrics, 'George Emil Palade' University of Medicine, Pharmacy, Science and Technology, \\ 540142 Târgu Mureş; ${ }^{2}$ Pediatric Clinic 1, Emergency County Hospital, 540139 Târgu Mureş; \\ ${ }^{3}$ Pediatric Nephrology Department, Emergency Clinical Hospital for Children, 400124 Cluj-Napoca; \\ ${ }^{4}$ Neurology Clinic, Clinical Recovery Hospital Cluj-Napoca, \\ 'Iuliu Hatieganu’ University of Medicine and Pharmacy, 400347 Cluj-Napoca, Romania
}

Received February 26, 2021; Accepted March 30, 2021

DOI: $10.3892 /$ etm.2021.10180

\begin{abstract}
One of the most frequent bacterial infections in children are urinary tract infections (UTIs). In recent years, an increasing incidence of UTIs caused by resistant bacterial strains has been observed, especially with extended-spectrum $\beta$-lactamase-producing Enterobacteriaceae that represent about $15 \%$ of UTIs. A retrospective study was performed comprising 331 pediatric cases with UTI. Our study aimed to detect the resistance of the uropathogens to common drugs used in UTI treatment. High resistance rates have been recorded for ampicillin, amoxicillin, trimethoprim/sulfamethoxazole (TMP/SMX), cefuroxime, and ciprofloxacin, among E.coli and Klebsiella. The multidrug-resistance (MDR) rate was detected in one-third of the uropathogens, among which more than half were isolated in patients with urinary tract abnormalities. Our study highlighted that nitrofurantoin, ceftriaxone, amikacin and carbapenem may be used for the empirical treatment for febrile or complicated UTI in children. This is the first comprehensive study that evaluates antibiotic resistance in UTIs in children, and their association with urinary tract abnormalities in Romania. As a result of this research, the protocol for initial empiric treatment of infants with febrile or complicated UTI should be modified considering a detailed and ongoing monitoring of local sensitivity of uropathogens to antimicrobial agents.
\end{abstract}

Correspondence to: Dr Iulia Cozea, Pediatric Clinic 1, Emergency County Hospital, 50 Gh. Marinescu Street, 540139 Târgu Mureş, Romania

E-mail: jullya_armean@yahoo.com

Abbreviations: aUTI, afebrile urinary tract infection; CFU, colony forming unit; CI, confidence interval; ESBL, extended-spectrum $\beta$-lactamase; MDR, multidrug resistance; TMP/SMX, trimethoprim/sulfamethoxazole; UTI, urinary tract infection; VUR, vesicoureteral reflux

Key words: children, multidrug resistance, uropathogen, infection

\section{Introduction}

Urinary tract infections (UTIs) represent one of the most frequent infectious diseases affecting humans, as well as an important public health issue with a significant economic burden (1). UTIs represent one of the most common bacterial infections in children and one of the main reasons for fever and antibiotic prescription $(2,3)$.

The incidence of the disease reaches $3 \%$ in neonates and is around $0.7 \%$ in infants up to 1 year. The prevalence of UTI in febrile infants is around 5\% (2). Up to $11 \%$ of girls and $7 \%$ of boys will have had a UTI by the age of 16 years, and recurrence of infection is common. Vesicoureteral reflux (VUR) is identified in up to $40 \%$ of children being investigated for a first UTI and it represents a risk factor but a weak predictor for renal parenchymal defects (4).

UTI is defined as a significant bacteriuria growth of a single pathogen: At least $10^{4}$ colony forming units (CFU) for catheter specimens and at least $10^{5} \mathrm{CFU}$ for midstream clean catch specimens) or $5 \times 10^{4} \mathrm{CFU}$ and significant pyuria in a patient with fever or other clinical symptoms (5-9). Recurrent UTIs are defined as repeated infections with a different pathogen agent, while relapsing UTIs represent repeated infections with the same pathogen $(5-7,10,11)$.

Up to $30 \%$ of infants and children experience recurrent infections during the first 6-12 months after the initial UTI. In the youngest infants, UTI symptoms differ significantly compared to older infants and children $(1,2)$.

UTIs are primarily caused by Gram-negative bacteria. The main pathogen responsible for uncomplicated cystitis and pyelonephritis is Escherichia coli followed by other species of Enterobacteriaceae, such as Proteus mirabilis and mostly Klebsiella pneumoniae, and by Gram-positive pathogens, such as Enterococcus faecalis and Staphylococcus saprophyticus (1).

Empiric antibiotic treatment should be initiated for suspected UTI in a sick child, and if necessary, changed later according to the sensitivity results for the isolated uropathogen. Guidelines recommend that empiric antibiotic treatment for suspected UTI should be based on local susceptibilities derived from available local epidemiological information $(5,9,12)$. 
In recent years, effective antibiotic treatment of UTIs in young children alleviates acute symptoms and may also limit long-term sequelae. Antibiotics should ideally be prescribed only to those who have a UTI, using an antibiotic with the narrowest effective spectrum. Treating pediatric UTIs in less than 3 days reduces the risk of acquiring kidney scars by $50 \%$ (13).

Currently, there is an alarming level of antimicrobial resistance which has developed in UTI pathogens as a result of improper and widespread use of antibiotics $(1,14)$.

Antimicrobial resistance is an internationally recognized threat to public health. The contribution of primary healthcare is of significant importance as this is where around $80 \%$ of all antibiotics used within the health service are prescribed (15). Antibiotic resistance in pediatric patients is increasing. Less than $50 \%$ of all pediatric UTIs are susceptible to commonly used antibiotics $(16,17)$. Antibiotic-resistant infections are most likely to be associated with greater morbidity and mortality and are associated with increased healthcare costs (15).

As for $E$. coli, resistance to third-generation cephalosporins and combined resistance to third-generation cephalosporins, fluoroquinolones, and aminoglycosides has increased significantly at the European Union/European Economic Area level between 2013 and 2016. Carbapenems are an important group of last-line antibiotics for the treatment of infections with multidrug-resistant (MDR) gram-negative bacteria such as Klebsiella pneumoniae and E. coli. In 2016, carbapenem resistance in E. coli remained rare, and most countries reported low resistant levels for Klebsiella pneumonia (18).

MDR is increasing worldwide, especially for commonly used antibiotics. Bacterial resistance to at least one antimicrobial in three or more classes defines MDR (19).

\section{Patients and methods}

Study sample and data source. A retrospective, transversal study was performed using 331pediatric patients diagnosed with UTI, aged between 2 weeks and 17 years, admitted to the Pediatric Clinic 1, Nephrology Department of the Emergency Clinical County Hospital (TârguMureş) and the Nephrology Department of the Emergency Clinical Hospital for Children (Cluj-Napoca, Romania), between January 2016 and December 2018.

Inclusion and exclusion criteria. We included all children with clinical and paraclinical signs of UTI. Exclusion criteria consisted of incomplete anamnestic, clinical or paraclinical data. If fever was absent, the UTI was classified as afebrile UTI (aUTI).

Laboratory methods. In general, antibiogram results were considered as susceptible, intermediate, or resistant; for the purpose of our study, intermediate and resistant isolates were considered collectively as non-susceptible. Extended-spectrum $\beta$-lactamase (ESBL)-producing strains were identified using double-disk synergy test.

Ethics. All mothers signed informed consent for their children. Our study was approved by the Ethics Committee of the University of Medicine and Pharmacy of Târgu Mureș (no. 259/July 11, 2019), and it was accepted according to the principles of the Helsinki Declaration.

Statistical analysis. Microsoft Office Excel package was used for data collection and GraphPadPrism v.5 (GraphPad Software, Inc.) for statistical analysis. We used discrete quantitative and binary qualitative variables. For the comparison of means, we used the Student's t-test with a significance threshold of $95 \%$ confidence interval (CI). In addition, inferential statistical test, such as Chi-square and analysis of variance (ANOVA) were applied.

\section{Results}

Patient characteristics. Among the 331 patients included in our study, the mean age was $4.13 \pm 4.48$ years. The study group was divided into age groups $(<1,1-3,3-6,6-14$ and 14-18 years. More than a third of isolates $(n=115,34.74 \%)$ were from patients younger than 1 year, followed by the group of age $1-3$ years $(n=79,23.86 \%)$, and the groups of 3-6 and 6-14 years with similar frequency $(n=51,15.42 \%$ and $\mathrm{n}=54,16.32 \%$ respectively), while the lowest number of cases was within the 14-18 year group $(n=32,9.66 \%)$ (Fig. 1).

With respect to sex distribution, urine samples were processed from 147 boys and184 girls (44.41/55.59\%). The sex ratio was $1: 1.25$, high lighting that UTIs are a more frequent pathology in girls. The male to female ratio varied according to age as follows: In the $<1$ year of age group, sex ratio favored boys 1.34:1 while in the other age groups, sex ratio was in favor of female patients: [1-3 year age group, 0.68:1; 3-6 year age group, 0.75:1; 6-14 year age group, 0.45:1; 14-18 year age group, 0.45:1 (Fig. 2).

More than half of the children [57.71\%, $n=191 / 331]$ had no other comorbidities while in $42.29 \%$ cases $(n=140 / 331)$ a urinary tract-abnormality was detected.

Uropathogens. E. coli was the most frequently identified uropathogen $(72.2 \%, 239 / 331)$, followed by Klebsiella spp. (8.15\%,27/331), Proteus spp.(6.65\%,22/331) and Pseudomonas aeruginosa $(5.75 \%$; 19/331) (Fig. 3). In contrast, the lowest frequency in our study group was noted for Enterococcus (2.72\%; 9/331), Enterobacter spp. (2.42\%; 8/331), Morganella morganii $(0.91 \% ; 3 / 331)$, Staph. aureus $(0.6 \% ; 2 / 331)$, and others $(0.6 \% ; 2 / 331)$. Extended spectrum beta-lactamase (ESBL) producing bacteria were also detected in a high percentage in our samples, $7.85 \%$ (26/331). The characteristics of these pathogens are presented in Table I.

UTIs caused by $E$. coli were more frequent in female patients $(n=151,63.17 \%)$ than in males $(n=88,36.83 \%)$ with statistical significance $(\mathrm{P}=0.0001)$, while those caused by Klebsiella and Proteus spp. were more frequent in boys $[\mathrm{n}=17$ $(62.96 \%)$ and $n=13(59.09 \%)]$ than in girls $[n=10(37.04 \%)$ and $\mathrm{n}=9(40.91 \%)$ ], but with no statistical significance $(\mathrm{P}=0.04$ and $=0.15)$ (Table I). Age distribution of the patients who presented with UTIs with E. coli is emphasized in Fig. 4.

The antimicrobial resistance pattern of the uropathogens can be observed in Table II. Both E. coli and Klebsiella showed high resistance to ampicillin, amoxicillin, TMP/SMX, cefuroxime and ciprofloxacine, respectively. E. coli remained 


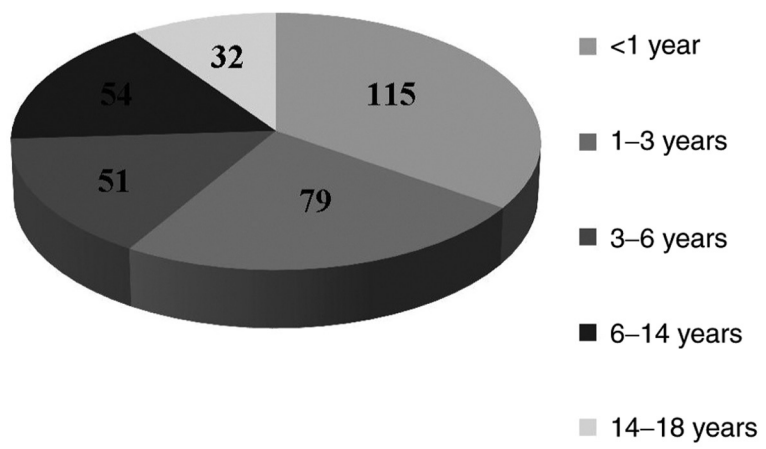

Figure 1. Age distribution of the cases with UTIs. UTI, urinary tract infection.

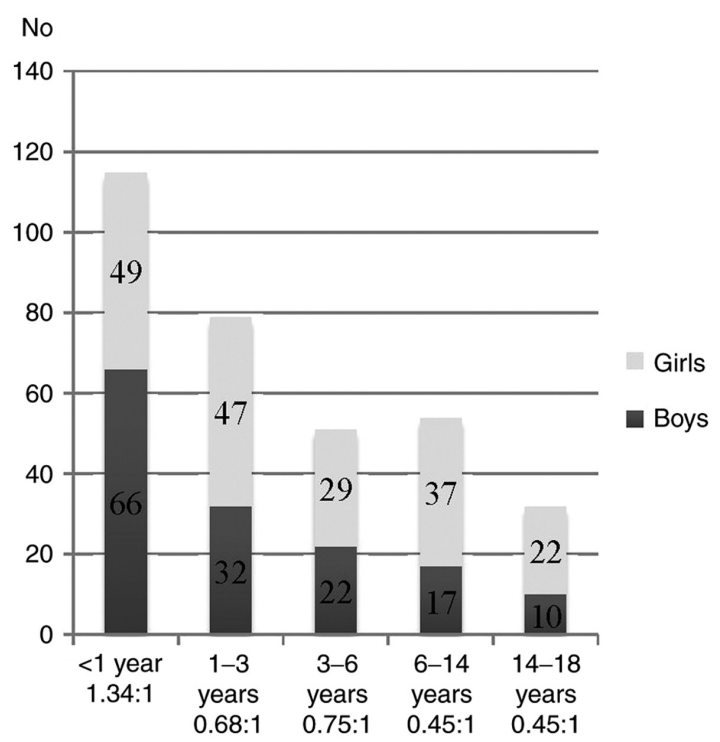

Figure 2. Sex distribution in the age groups and sex ratio.

susceptible to nitrofurantoin, ceftriaxone, meropenem while Klebsiella to amikacin, colistin and meropenem (Figs. 5 and 6).

Out of the total of 331 UTIs, a significant percentage of cases presented with associated urinary tract malformations $(\mathrm{n}=140,42.29 \%)$. This condition entailed a higher proportion of MDR of the involved uropathogens. In other words, MDR was detected in $34.13 \%$ of the uropathogens, among which $56.63 \%$ were isolated in patient with urinary tract malformation (Fig. 7). Analyzing a contingence table, we obtained a positive correlation between these variables $(\mathrm{P}=0.0001$, OR 2.44), meaning that urinary tract malformations are a predisposing factor for UTIs with MDR uropathogens.

From the 239 cases diagnosed with $E$. coli infection, $32.63 \%(78 / 239)$ presented a urinary tract abnormality, and $39.74 \%$ (31/78) with associated MDR. Also, in this instance, statistically, urinary tract abnormalities significantly influence the occurrence of a UTI caused by a MDR E. coli $(\mathrm{P}=0.005$, OR 2.29).

\section{Discussion}

Strengths and limitations. To the best of our knowledge, this is the first widespread research that evaluates antibiotic

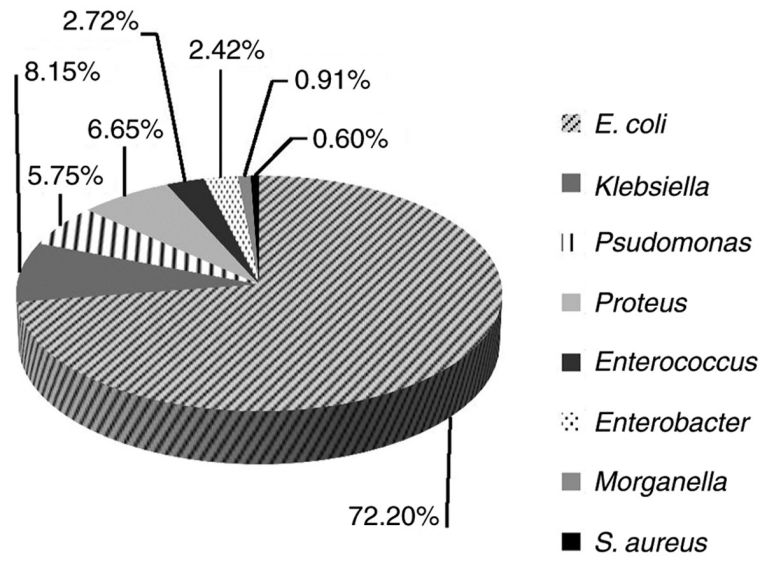

Figure 3. Uropathogen distribution.

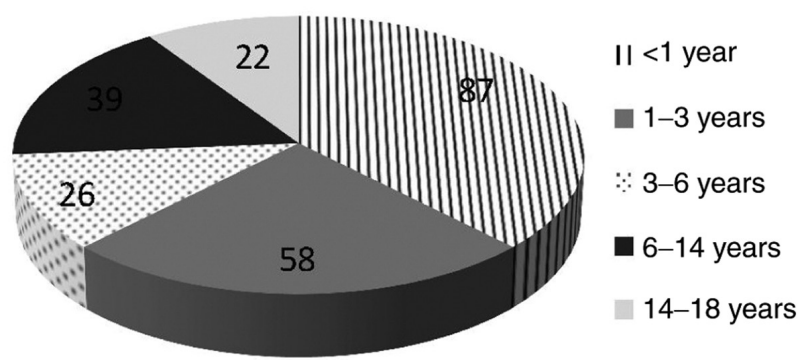

Figure 4. Age distribution of the cases with E. coli UTI. UTI, urinary tract infection.

resistance in childhood UTIs, and their association with urinary tract abnormalities in Romania.

E. coli and Klebsiella represented common uropathogens in children admitted to both nephrology departments involved. In this study, the frequency of infection with $E$. coli and Klebsiella were similar with studies from Nepal and Turkey $(20,21)$.

Of the 331 patients, 184 (55.58\%) were female compared with a study of Vazouras et al where the female proportion was $72.2 \%$ (22). The cause may be the higher rate of urinary tract abnormalities in our study group.

In the study performed by Vazouras et al, $11.3 \%$ (26/230) of the evaluated children had urinary tract-associated abnormalities (22) compared with our study where a 3.5-time higher rate of urinary tract-associated abnormalities were observed. The explanation may be that our study group was from two nephrology centers.

Similar to other pediatric studies on the same subject $(2,20,22), E$. coli was the most frequently encountered etiological agent in our research as well.

In a recent research in our country, E. coli, Klebsiella spp., Enterococcus spp., Morganella morganii, Proteus spp., and Enterobacter spp. represented the leading etiology for UTIs (53.3, 10.6, 5.2, 5.2, 4.5, and 3.9\%, respectively), results that are in part similar to our findings (2). When compared with our age-matched group, we found an occurrence of 87/115 (75.65\%) for E. coli, 11/115 (9.56\%) for Klebsiella spp., 5/115 (4.34\%) for Enterococcus spp., 3/115 (2.6\%) for Proteus spp., and 3/115 (2.6\%) for Enterobacter spp. 
Table I. Distribution of the uropathogens.

\begin{tabular}{|c|c|c|c|c|c|}
\hline Uropathogens & $\begin{array}{c}\text { Total }(\mathrm{N}=331) \\
\mathrm{n}(\%)\end{array}$ & $\begin{array}{l}\text { ESBL } \\
\mathrm{n}(\%)\end{array}$ & $\begin{array}{l}\text { Girls } \\
\mathrm{n}(\%)\end{array}$ & $\begin{array}{l}\text { Boys } \\
\mathrm{n}(\%)\end{array}$ & P-value \\
\hline E. coli & $239(72.20)$ & $19(7.95)$ & $151(63.17)$ & $88(36.83)$ & 0.0001 \\
\hline Klebsiella spp. & $27(8.15)$ & $5(18.51)$ & $10(37.04)$ & $17(62.96)$ & 0.0400 \\
\hline Pseudomonas aeruginosa & $19(5.75)$ & - & $9(47.36)$ & $10(52.64)$ & - \\
\hline Proteus spp. & $22(6.65)$ & $2(0.60)$ & $9(40.90)$ & $13(59.10)$ & 0.1500 \\
\hline Enterococcus & $9(2.72)$ & - & $3(33.33)$ & $6(66.67)$ & - \\
\hline Enterobacter spp. & $8(2.42)$ & - & - & 8 & - \\
\hline Morganella morgani & $3(0.91)$ & - & $1(33.33)$ & $2(66.67)$ & - \\
\hline Staph. Aureus & $2(0.60)$ & - & - & 2 & - \\
\hline Others & $2(0.60)$ & - & - & 2 & - \\
\hline
\end{tabular}

ESBL, extended-spectrum $\beta$-lactamase.

Table II. Resistance patterns of the uropathogens.

\begin{tabular}{|c|c|c|c|c|c|c|c|}
\hline ATB/Uropathogen & $\begin{array}{c}\text { E. coli } \\
(\%)\end{array}$ & $\begin{array}{c}\text { Klebsiella } \\
(\%)\end{array}$ & $\begin{array}{c}\text { Pseudomonas } \\
(\%)\end{array}$ & $\begin{array}{l}\text { Proteus } \\
(\%)\end{array}$ & $\begin{array}{c}\text { Enterococus } \\
(\%)\end{array}$ & $\begin{array}{c}\text { Morganella } \\
(\%)\end{array}$ & $\begin{array}{c}\text { Enterobacter } \\
(\%)\end{array}$ \\
\hline Nalidixic acid & 7.11 & 1.81 & $<1$ & $<1$ & $<1$ & $<1$ & $<1$ \\
\hline Amikacin & 7.94 & $<1$ & $<1$ & $<1$ & $<1$ & $<1$ & $<1$ \\
\hline Amoxicillin & 33.05 & 6.04 & $<1$ & 3.62 & $<1$ & 1.25 & 1.81 \\
\hline Ampicillin & 56.48 & 7.85 & $<1$ & 5.1 .3 & $<1$ & 1.25 & 2.09 \\
\hline Cefepime & 7.94 & 4.53 & 1.25 & 2.09 & $<1$ & $<1$ & 2.09 \\
\hline Cefotaxime & 10.04 & 4.53 & $<1$ & 2.09 & 1.25 & $<1$ & 1.81 \\
\hline Ceftazidime & 10.46 & 3.32 & 1.67 & 1.25 & 1.25 & $<1$ & 2.09 \\
\hline Ceftriaxone & 3.34 & 1.25 & $<1$ & $<1$ & 1.25 & $<1$ & 1.67 \\
\hline Cefuroxime & 12.13 & 1.25 & 1.25 & 1.67 & 1.25 & $<1$ & 2.09 \\
\hline Ciprofloxacin & 12.13 & 3.92 & $<1$ & 1.25 & 1.67 & $<1$ & 1.25 \\
\hline Colistin & 1.67 & $<1$ & $<1$ & $<1$ & $<1$ & $<1$ & $<1$ \\
\hline Ertapenem & 0.83 & 2.09 & $<1$ & $<1$ & $<1$ & $<1$ & 1.25 \\
\hline Gentamicin & 7.11 & 3.02 & 3.32 & 1.67 & 1.81 & $<1$ & 1.25 \\
\hline Imipenem & 2.09 & $<1$ & $<1$ & $<1$ & $<1$ & $<1$ & $<1$ \\
\hline Linezolid & $<1$ & $<1$ & $<1$ & $<1$ & $<1$ & $<1$ & $<1$ \\
\hline Meropenem & 1.25 & $<1$ & $<1$ & $<1$ & $<1$ & $<1$ & $<1$ \\
\hline Netilmicin & $<1$ & $<1$ & $<1$ & $<1$ & $<1$ & $<1$ & $<1$ \\
\hline Nitrofurantoin & 6.69 & 1.81 & $<1$ & 1.81 & $<1$ & $<1$ & $<1$ \\
\hline Norfloxacin & 15.06 & 4.23 & $<1$ & 1.67 & $<1$ & $<1$ & $<1$ \\
\hline Oxacillin & $<1$ & $<1$ & $<1$ & $<1$ & $<1$ & $<1$ & $<1$ \\
\hline Piperacillin & 7.94 & 0.83 & $<1$ & $<1$ & $<1$ & $<1$ & $<1$ \\
\hline Piperacillin/tazobactam & 10.04 & 2.41 & 1.25 & $<1$ & $<1$ & $<1$ & 2.09 \\
\hline Streptomycin & $<1$ & $<1$ & $<1$ & $<1$ & 1.67 & $<1$ & $<1$ \\
\hline Teicoplanin & $<1$ & $<1$ & $<1$ & $<1$ & $<1$ & $<1$ & $<1$ \\
\hline Tetracycline & $<1$ & $<1$ & $<1$ & $<1$ & $<1$ & $<1$ & $<1$ \\
\hline Ticarcillin & 0.41 & $<1$ & $<1$ & $<1$ & $<1$ & $<1$ & $<1$ \\
\hline Ticarcillin/clavulanic acid & 0.83 & $<1$ & 1.25 & $<1$ & $<1$ & $<1$ & $<1$ \\
\hline Tigecycline & 1.25 & $<1$ & $<1$ & $<1$ & $<1$ & $<1$ & $<1$ \\
\hline Trimethoprim & 24.68 & 3.92 & 1.67 & 2.71 & 1.25 & 1.25 & 1.25 \\
\hline Vancomycin & $<1$ & $<1$ & $<1$ & $<1$ & $<1$ & $<1$ & $<1$ \\
\hline
\end{tabular}

In their research, Vazouras et al found that the main causative organism was E. coli $(79.2 \%)$ with high reported resistance rates to ampicillin (42.0\%), TMP/SMX (26.5\%), and amoxicillin/clavulanic acid (12.2\%); lower resistance rates 


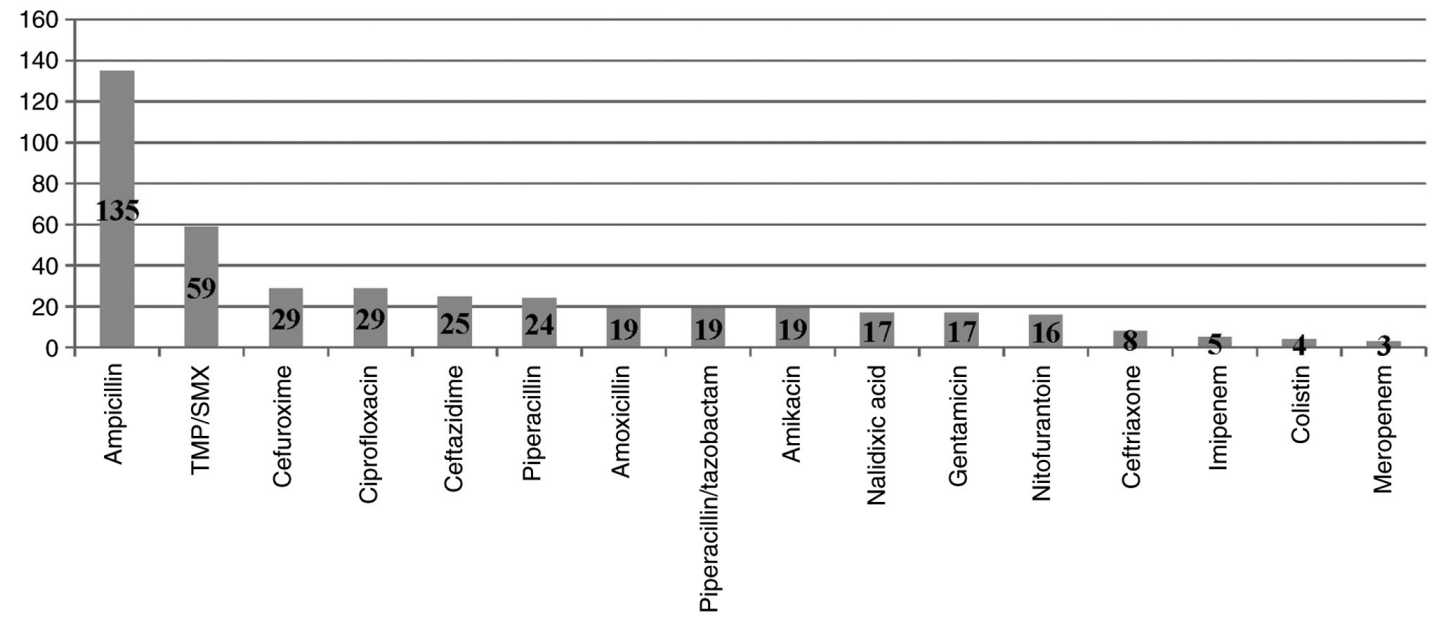

Figure 5. E. coli resistance pattern.

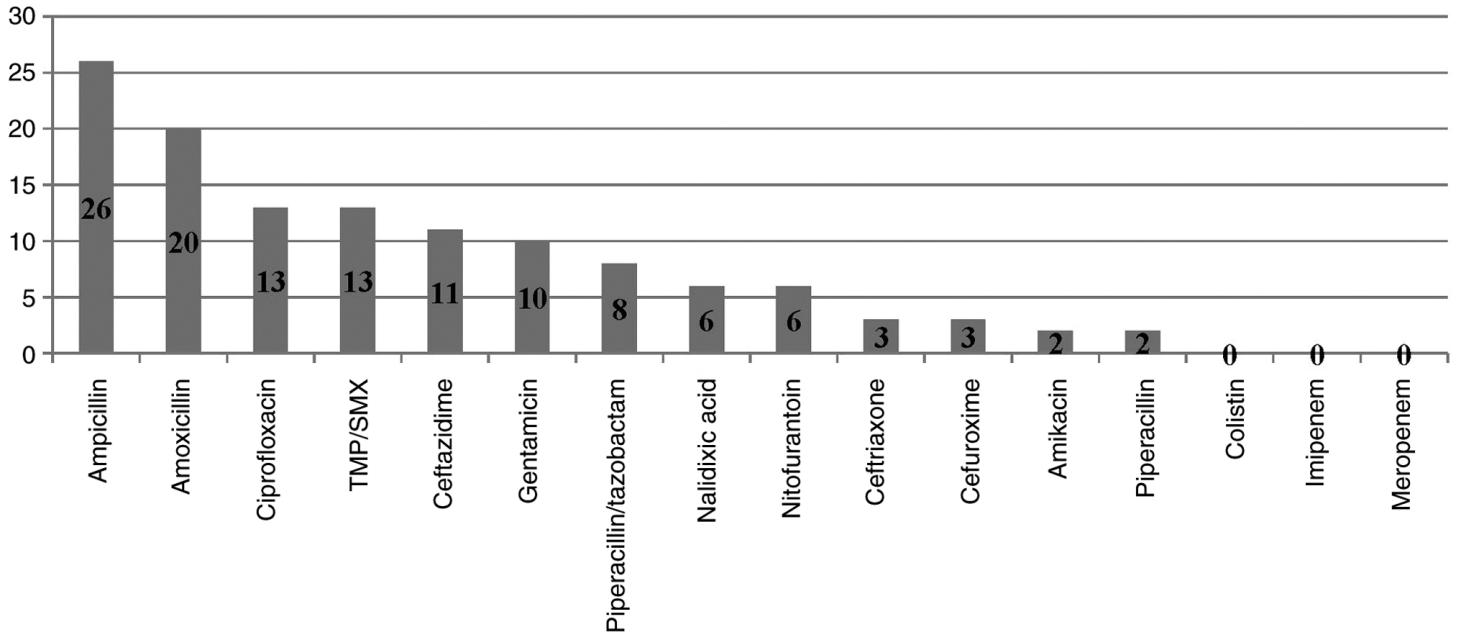

Figure 6. Klebsiella resistance pattern.

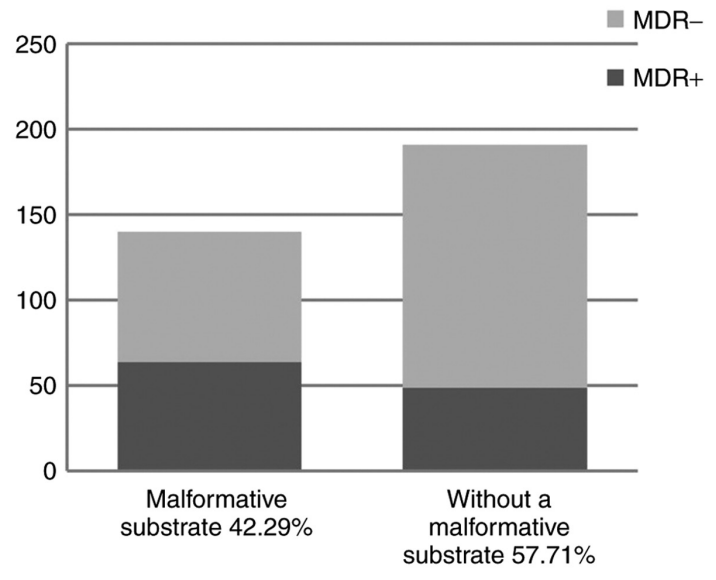

Figure 7. Association between the presence of a congenital anomaly and UTI with MDR uropathogens. UTI, urinary tract infection; MDR, multidrug-resistant.

were identified for third-generation cephalosporins (1.7\%), nitrofurantoin $(2.3 \%)$, ciprofloxacin $(1.4 \%)$ and amikacin $(0.9 \%)(22)$. These results are only partly similar to ours.
Low resistance rates of E. coli and Klebsiella to piperacillin/tazobactam, meropenem, nalidixic acid, chloramphenicol and colistin were found by Falup-Pecurariu $e t a l$, these results being comparable with the present study (2).

In our cohort, the ESBL-positive UTIs were $7.85 \%(n=26)$ compared with a lower incidence in a recent study (1.7\%) (22), while another study in Northern Greece exposed an incidence of ESBL-positive UTIs of 10.4\% (23).

Our research depicted that there is a higher chance for UTIs due to ESBL-producing pathogens in children with urinary tract abnormalities and those receiving antimicrobial prophylaxis. This finding is comparable with the results of another study (23).

In the pediatric group with non-ESBL-positive UTIs, a higher ratio of urinary tract anomalies as well as antimicrobial prophylaxis were observed $(\mathrm{P}<0.05)$, compared to those from ESBL-positive UTI group. This is in disagreement with the conclusion of a recent study (23).

A high incidence of ESBL-positive uropathogens was revealed by Falup-Pecurariu et al (2) compared to our research [55 of $68(80.9 \%)$ E. coli vs. 5 of $87(5.75 \%)$ ] were ESBL-positive; 15/35 (42.9\%) of the Klebsiella spp. vs. 2 of 11 (18.2\%) were ESBL-positive. 
Regarding the MDR UTI cases, a prolonged antimicrobial prophylaxis and presence of urinary tract anomalies have been considered as risk factors (24).

Current literature data suggest the effectiveness of fosfomycin against MDR and drug-resistant bacteria (25). This may be extrapolated to us as there is very low use of this drug in our centers.

Our study indicates that nitrofurantoin, ceftriaxon, amikacin, and carbapenem may be used for the empirical treatment of febrile or complicated UTIs in children. Our study results are comparative with those achieved by Raya et al (20).

These results are however contradicted by a local study (2), where only $6 \%$ of infants had previous renal anomalies compared to our study where we had a significant higher frequency.

Current findings emphasize that male patients are more often diagnosed with UTIs in the first year of life while female patients are diagnosed at approximately 3 years of age (26). Our study sustains this idea, statistically confirming that in the first year of life almost $60 \%$ of the patients diagnosed with UTIs $(57.39 \%, 66 / 115)$ were male, thus obtaining a $1.34: 1$ sex ratio. However, our overall ratio of male and female patients with UTIs was in favor of girls $1: 1.25$, this result being comparable with other studies (26).

In conclusion, initial therapy for UTI is originally empirical until the results of a urine culture are ready. Therefore, it is mandatory to know the local resistance of uropathogens to antimicrobial agents as well as the risk factors for UTI due to resistant pathogens such as ESBL.

The results of this study may influence empirical therapy for UTIs until the ESBL production has been confirmed. Since local antimicrobial sensitivities vary significantly, local guidelines and close monitoring should be provided to coordinate empiric antibiotic treatment.

\section{Acknowledgements}

Not applicable.

\section{Funding}

No funding was received.

\section{Availability of data and materials}

Further information regarding the data of the present study is available from the corresponding author upon reasonable request.

\section{Authors' contributions}

$\mathrm{CD}$ and IC contributed to the conception and design of the research. $\mathrm{CD}$ and $\mathrm{IC}$ wrote the first draft of the manuscript. $\mathrm{CD}, \mathrm{IC}, \mathrm{DD}, \mathrm{CA}$ wrote sections of the manuscript. DD, AAA, and $\mathrm{CA}$ analyzed previous literature studies and revised the manuscript critically for important intellectual content. All authors contributed to manuscript revision, read and approved the submitted version.

\section{Ethics approval and consent to participate}

Our study was approved by the Ethics Committee of the University of Medicine and Pharmacy of Târgu Mureș (no. 259/July 11, 2019). All mothers signed informed consent for their children.

\section{Patient consent for publication}

Not applicable.

\section{Competing interests}

The authors declare that they have no competing interests.

\section{References}

1. Mazzariol A, Bazaj A and Cornaglia G: Multi-drug-resistant gram-negative bacteria causing urinary tract infections: A review. J Chemother 29 (Suppl 1): S2-S9, 2017.

2. Falup-Pecurariu O, Leibovitz E, Bucur M, Lixandru R, Bleotu L and Falup-Pecurariu C: High resistance rates to 2nd and 3rd generation cephalosporins, ciprofloxacin and gentamicin of the uropathogens isolated in young infants hospitalized with first urinary tract infection. Biomed Res 28: 8774-8779, 2017.

3. Ismaili K, Wissing KM, Lolin K, Le PQ, Christophe C, Lepage P and Hall M: Characteristics of first urinary tract infection with fever in children: A prospective clinical and imaging study. Pediatr Infect Dis J 30: 371-374, 2011.

4. Larcombe J: Urinary tract infection in children: Recurrent infections. BMJ Clin Evid 2015: 0306, 2015.

5. NICE. Urinary tract infection in under 16s: Diagnosis and management, clinical guideline CG54. National Institute for Health and care Excellence,2017. Available from:https://www.nice.org.uk/guidance/ cg54/resources/urinary-tract-infection-in-under-16s-diagnosis-andmanagement-pdf-975507490501.

6. Stein R, Dogan HS, Hoebeke P, Kočvara R, Nijman RJ, Radmayr C and Tekgül S: European association of urology; European society for pediatric urology: Urinary tract infections in children: EAU/ESPU guidelines. Eur Urol 67: 546-558, 2015.

7. Armean I, Meliț LE and Duicu C: A rare case of urinary tract infection with Burkholderia cepacia in a male child. Ro J Infect Dis 21: 70-73, 2018.

8. Primack W, Bukowski T, Sutherland R, Gravens-Mueller L and Carpenter M: What urinary colony count indicates a urinary tract infection in children? J Pediatr 191: 259-261.e1, 2017.

9. Duicu C, Armean I and Aldea C: New insights in treatment options in pediatric urinary tract infection. Acta Med Marisiensis 65: 7-11, 2019.

10. Gorczyca D, Augustyniak D, Basiewicz-Worsztynowicz B and Karnas-Kalemba W: Serum and urinary MIP-1 $\alpha$ and IP-10 levels in children with urinary tract infections. Adv Clin Exp Med 23: 933-938, 2014.

11. Becknell B, Schober M, Korbel L and Spencer JD: The diagnosis evaluation and treatment of acute and recurrent pediatric urinary tract infections. Expert Rev Anti Infect Ther 13: 81-90, 2015.

12. Butler CC, O'Brien K, Wootton M, Pickles T, Hood K, Howe R, Waldron CA, Thomas-Jones E, Dudley J, Van Der Voort J, et al: Empiric antibiotic treatment for urinary tract infection in preschool children: Susceptibilities of urine sample isolates. Fam Pract 33: 127-132, 2016.

13. Coulthard MG, Lambert HJ, Vernon SJ, Hunter WE, Keir MJ and Matthews JN: Does prompt treatment of urinary tract infection in preschool children prevent renal scarring: Mixed retrospective and prospective audits. Arch Dis Child 99: 342-347, 2014.

14. Bonkat G, Bartoletti R, Bruyère F, Cai T, Geerlings SE, Köves B, Schubert $\mathrm{S}$ and Wagenlehner F: EAU guidelines on urological infections, 2017. Available from: https://uroweb.org/wp-content/ uploads/19-Urological-infections_2017_web.pdf.

15. Bryce A, Hay AD, Lane IF, Thornton HV, Wootton M and Costelloe C: Global prevalence of antibiotic resistance in paediatric urinary tract infections caused by Escherichia coli and association with routine use of antibiotics in primary care: Systematic review and meta-analysis. BMJ 352: i939, 2016.

16. Saperston KN, Shapiro DJ, Hersh AL and Copp HL: A comparison of inpatient versus outpatient resistance patterns of pediatric urinary tract infection. J Urol 191 (Suppl 5): S1608-S1613, 2014. 
17. Prabhu A, Taylor P, Konecny P and Brown MA: Pyelonephritis: What are the present day causative organisms and antibiotic susceptibilities? Nephrology (Carlton) 18: 463-467, 2013.

18. Summary of the latest data on antibiotic resistance in the European Union. EARS-Net surveillance data. ECDC November, 2017. Available from: https://www.ecdc.europa.eu/sites/default/ files/documents/EAAD\%20EARS-Net\%20summary.pdf.

19. Magiorakos AP, Srinivasan A, Carey RB, Carmeli Y, Falagas ME, Giske CG, Harbarth S, Hindler JF, Kahlmeter G, Olsson-Liljequist $\mathrm{B}$, et al: Multidrug-resistant, extensively drug-resistant and pandrug-resistant bacteria: An international expert proposal for interim standard definitions for acquired resistance. Clin Microbiol Infect 18: 268-281, 2012.

20. Raya GB, Dhoubhadel BG, Shrestha D, Raya S, Laghu U, Shah A, Raya BB, Kafle R, Parry CM and Ariyoshi K: Multidrug-resistant and extended-spectrum beta-lactamase-producing uropathogens in children in Bhaktapur, Nepal. Trop Med Health 48: 65, 2020.

21. Shakya P, Shrestha D, Maharjan E, Sharma VK and Paudyal R: ESBL production among $E$. coli and Klebsiella spp. causing urinary tract infection: A hospital based study. Open Microbiol J 11: 23-30, 2017.
22. Vazouras K, Velali K, Tassiou I, Anastasiou-Katsiardani A, Athanasopoulou K, Barbouni A, Jackson C, Folgori L, Zaoutis T, Basmaci R and Hsia Y: Antibiotic treatment and antimicrobial resistance in children with urinary tract infections. J Glob Antimicrob Resist 20: 4-10, 2020.

23. Dotis J, Printza N, Marneri A, Gidaris D and Papachristou F: Urinary tract infections caused by extended-spectrum betalactamase-producing bacteria in children: A matched casecontrol study. Turk J Pediatr 55: 571-574, 2013.

24. Duicu C, Kiss E, Simu I and Aldea C: A rare case of double-system with ectopic ureteral openings into vagina. Front Pediatr 6: 176, 2018.

25. Williams PC: Potential of fosfomycin in treating multidrug-resistant infections in children. J Paediatr Child Health 56: 864-872, 2020.

26. Woo B, Jung Y and Kim HS: Antibiotic sensitivity patterns in children with urinary tract infection: Retrospective study over 8 years in a single center. Child Kidney Dis 23: 22-28, 2019. 